\title{
Control Design for an Advanced Geared Turbofan Engine
}

Jeffryes W. Chapman,

Vantage Partners, LLC

Jonathan Litt,

NASA Glenn Research Center

AIAA Joint Propulsion Conference

Atlanta, GA

July 10-12, 2017 


\section{Outline}

- Background and Objective

- Simulation Description

- Engine Model

- Controller Design

- Actuator Hardware Model Design

- Mission Demonstration

- Sample Study

- Details on Model Operation

- Summary 


\section{Background}

- As preparation for the next generation of aircraft, advanced highefficiency engine concepts have been developed to demonstrate new technology.

The Advanced Geared Turbofan, 30,000 lbf (AGTF30) engine simulation was developed to investigate possible next generation engine system designs including:

1. Ultra-high bypass

2. Small core

3. Variable area fan nozzle (VAFN)

- Objective:

- Detail the generation of a full envelope, classical control system for the AGTF30 engine.

- Highlight challenges associated with the control system concept of this advanced engine.

- Purpose:

- To provide a dynamic platform for next generation engine system research. 


\section{Modeling Platform}

- The AGTF30 was created using the Toolbox for the Modeling and Analysis of Thermodynamic Systems (T-MATS)

- Modular thermodynamic modeling framework created by NASA

- Built on top of MATLAB/Simulink

- Package highlights:

- General thermodynamic simulation design framework

- Variable input system solvers

- Advanced turbo-machinery block sets

- Control system block sets

- Non-proprietary, free of export restriction and open source with +4500 downloads, https://github.com/nasa/T-MATS/releases

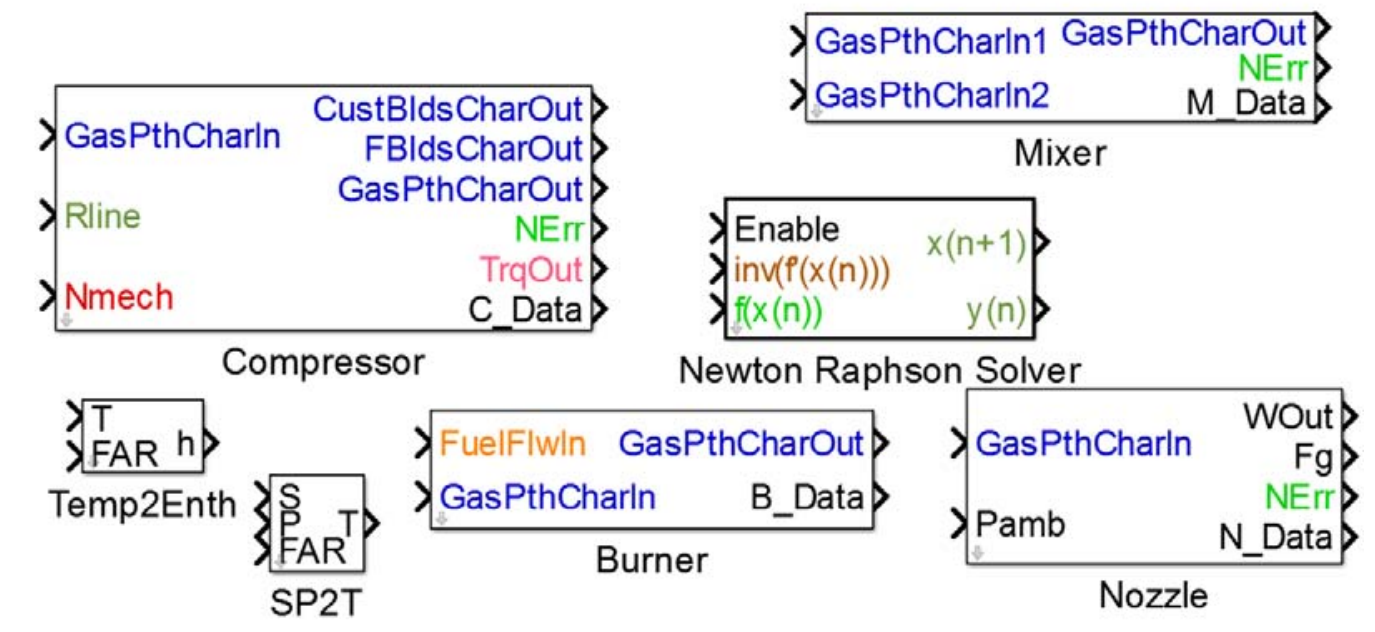




\section{Engine Model Description}

- Advanced Geared Turbofan features

- Variable area fan nozzle (VAFN)

- Dual spool with low pressure shaft connected to fan via a gear box

- Performance

- $\mathrm{BPR}=24, \mathrm{OPR}=50, \mathrm{TIT}=3000, \mathrm{TSFC}=0.46$ at cruise

- 30,000 lbf takeoff thrust

- Control Effectors: VAFN, fuel flow (Wf), and variable bleed valve (VBV)

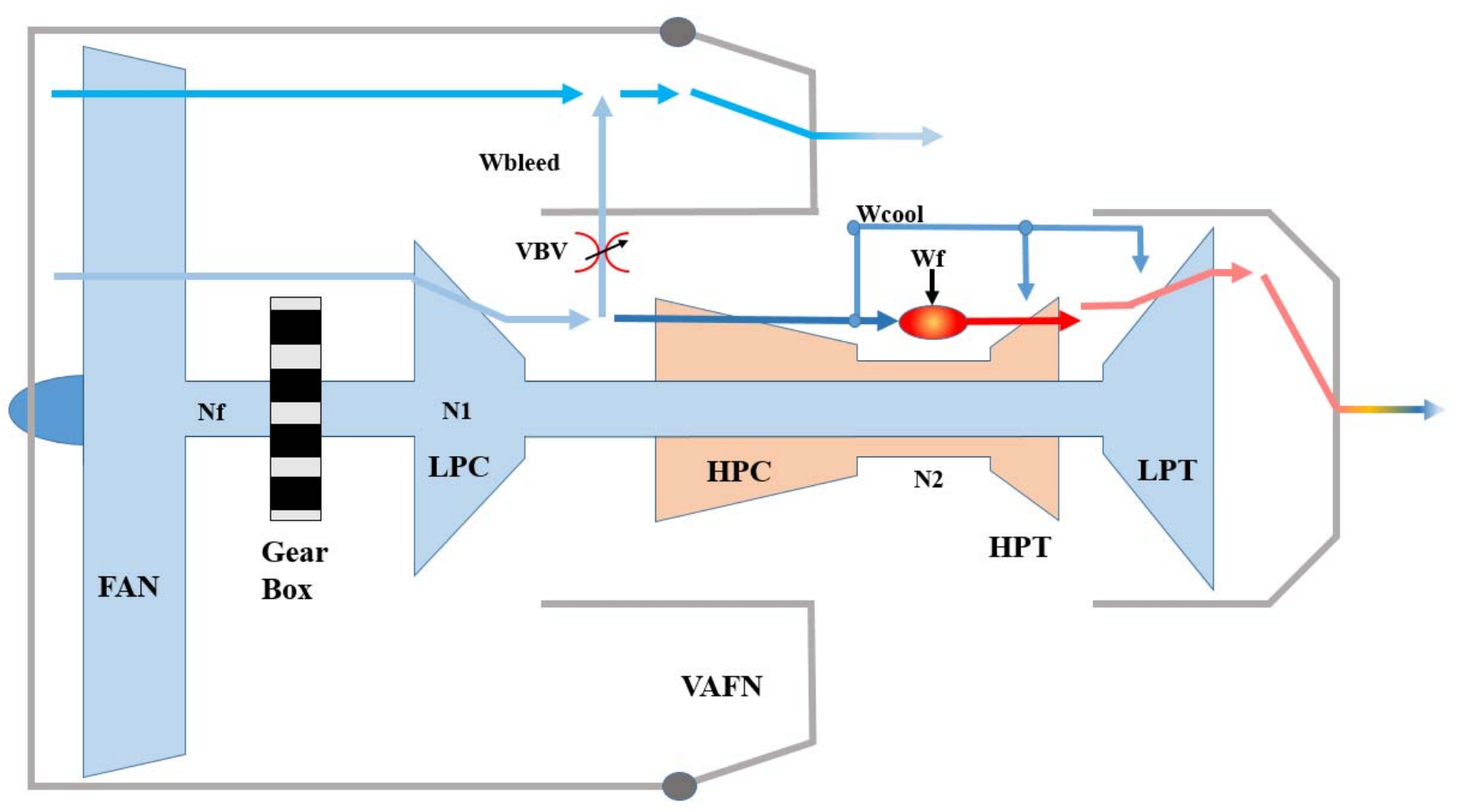




\section{Fuel Control Architecture}

- Fuel Control methodology based on literature

- Power Management generates fan speed request based on power lever angle (PLA)

- Fan speed controller generates a fuel flow request

- Sets of limiters adjust the fuel flow request to operate the engine safely, avoiding engine stall, exceeding structural limits, combustor blowout, etc.

- Controllers utilize PI method, tuned to meet requirements throughout the envelope
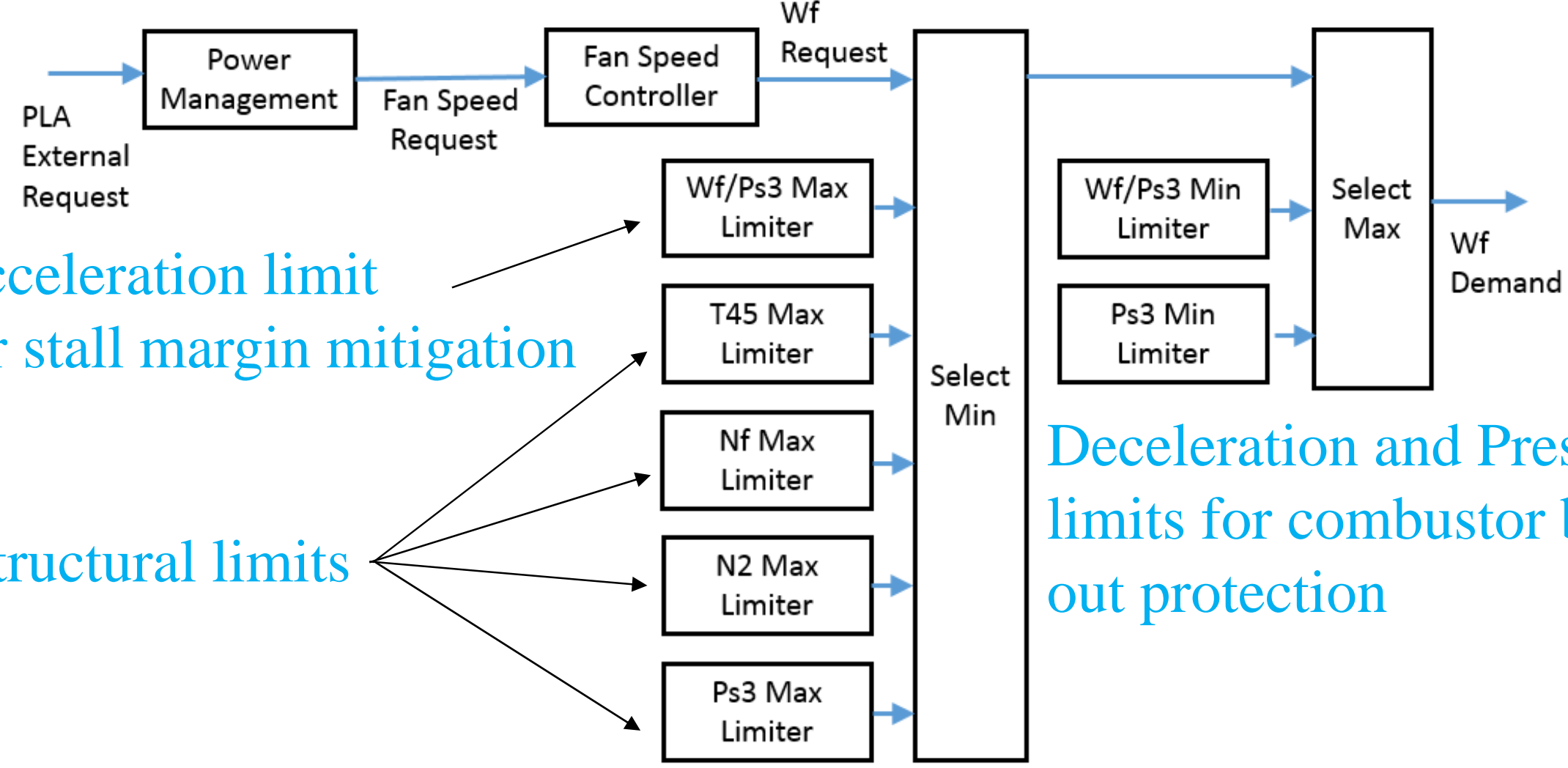

Deceleration and Pressure limits for combustor blow out protection 


\section{Fuel Control Power Management}

- Fuel is the main effector to control the engine, and thrust is the dominant engine output.

- AGTF30 utilizes a classical control strategy

- Thrust cannot be sensed, so fan speed ( $\mathrm{Nf}$ ) was selected as the thrust surrogate

- Advantages of using fan speed:

- Generally linear relationship with thrust (given constant environment and consistent variable geometry positions).

- Sensor availability and low susceptibility to noise

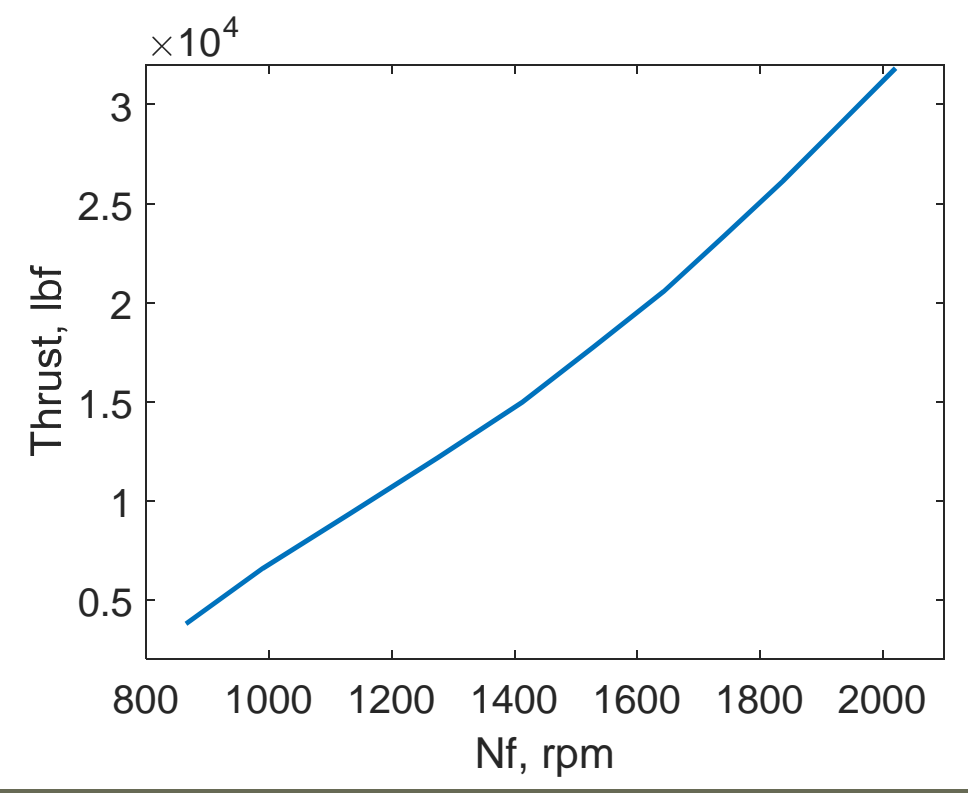

Relationship between Thrust and Nf sea level and static conditions 


\section{Fuel Control Tuning}

- PI controller gains tuned to ideal values throughout envelope

- Linear models were generated throughout the envelope and at various power levels

- PI controller gains were tuned for each defined linear model.

- Gains were collected into schedules that provide the optimum gain at each operational point.

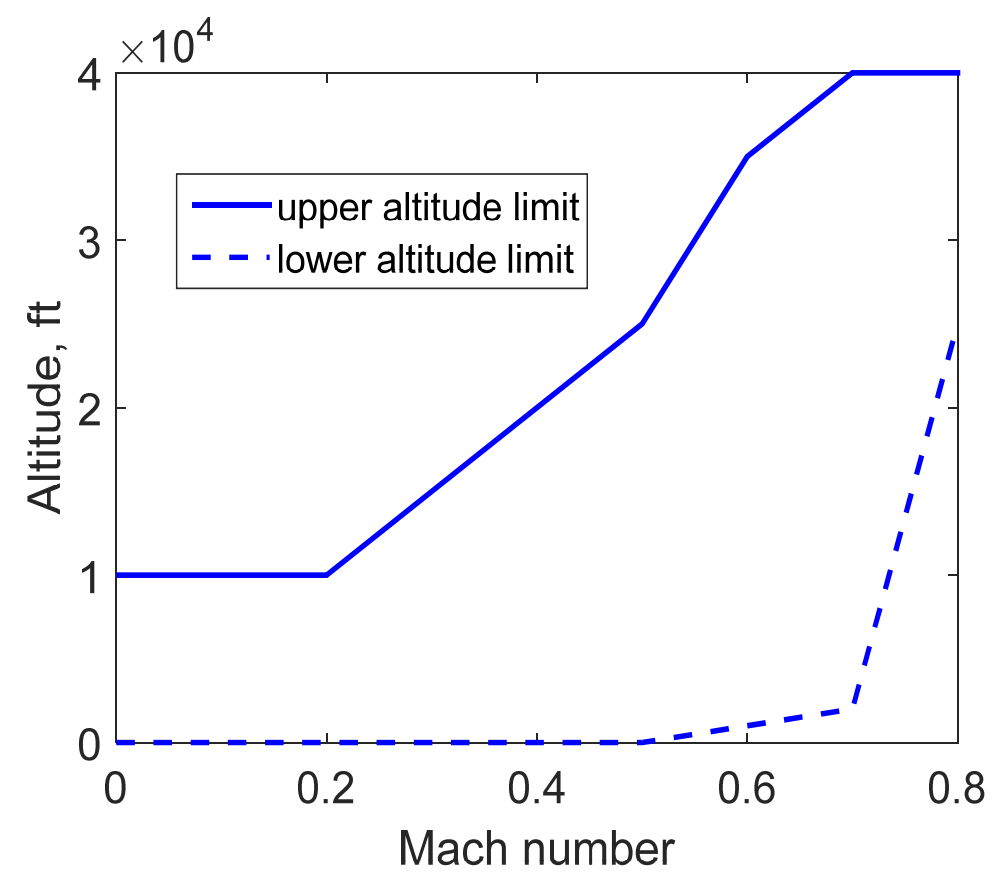

Operational Envelope

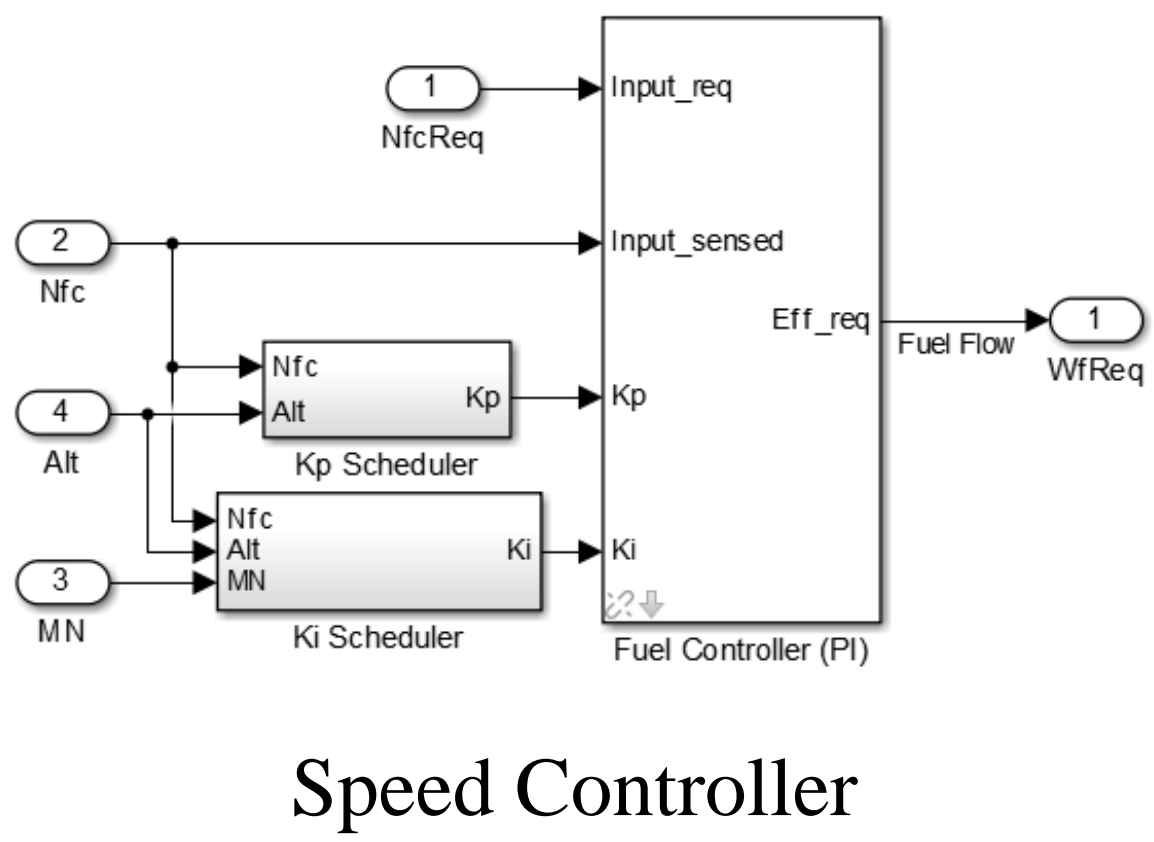




\section{Setting Fuel Limiters}

- Limiters designed to maintain safe engine operation

- Set to avoid engine stall, structural limits, and engine blow out.

- Structural limits based on anticipated next generation requirements.

- Stall mitigated by limiting acceleration with a maximum Wf/Ps3 limit

- Hypothetical engine blow out mitigated with minimum Wf/Ps3 and Ps3 limits

- Limiters tuned to allow acceleration from idle to 95\% takeoff power within 5 seconds

- Minimum stall margin requirement set to $8 \%$.

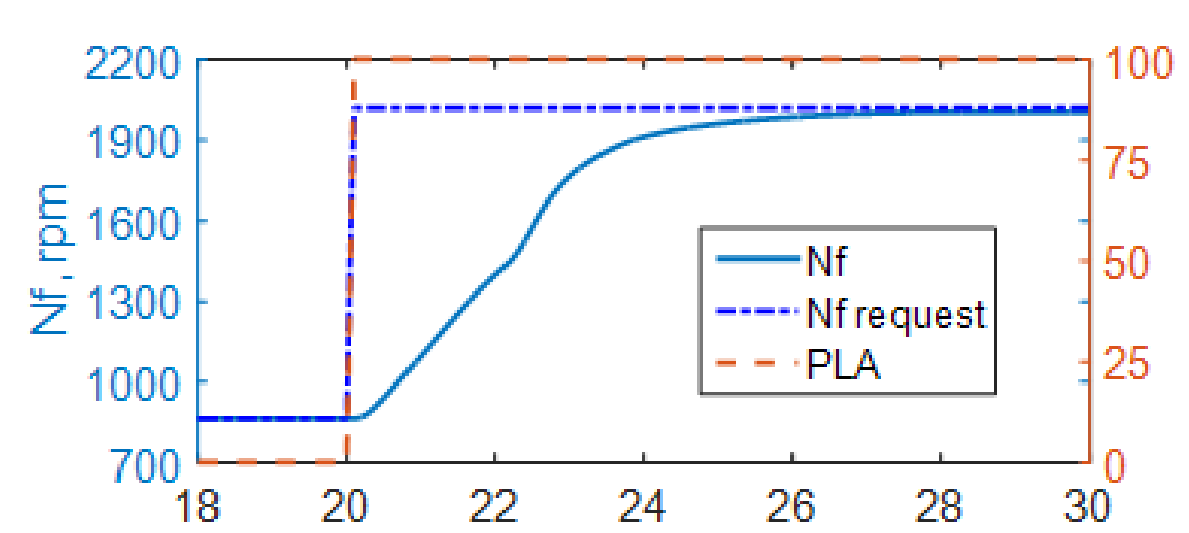

(a) Time, s

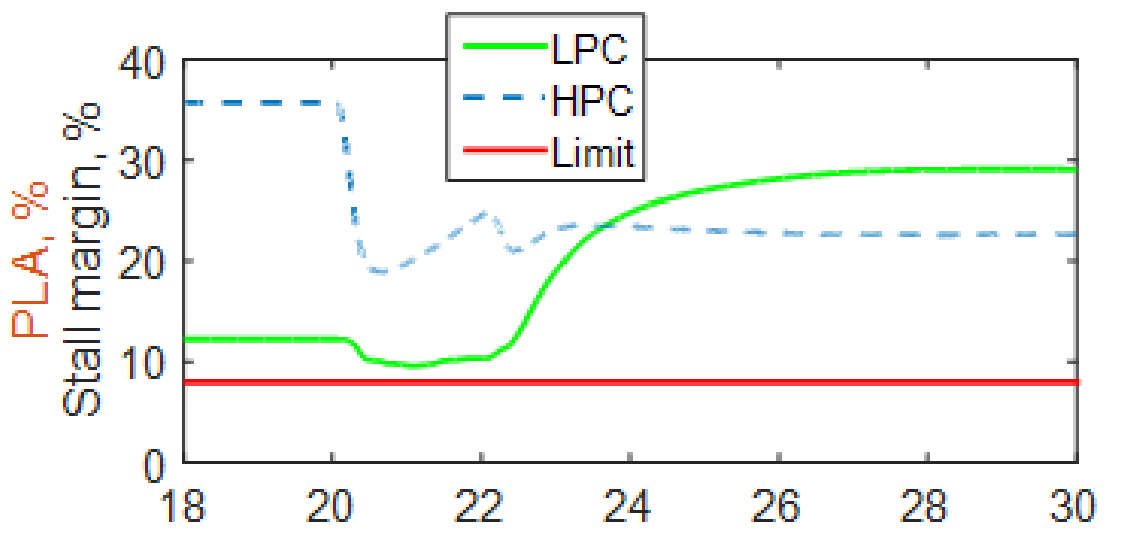

(b) Time, s 


\section{VBV Control Architecture}

- Variable bleed valve opens to reduce low pressure compressor (LPC) pressure ratio (PR), increasing stall margin.

- Schedules constructed to maintain $10 \%$ stall margin during steady-state operation.

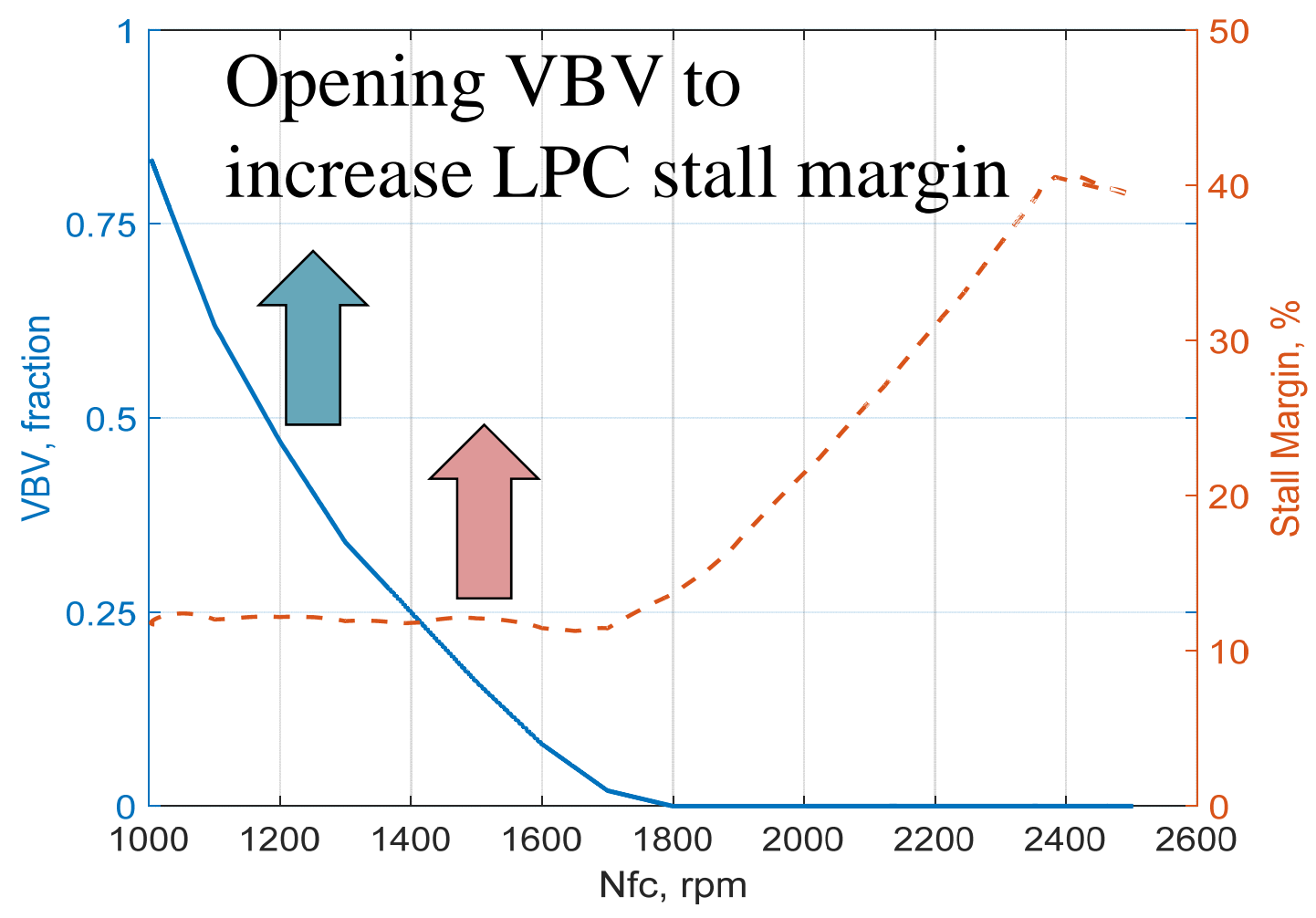




\section{VAFN Control Architecture}

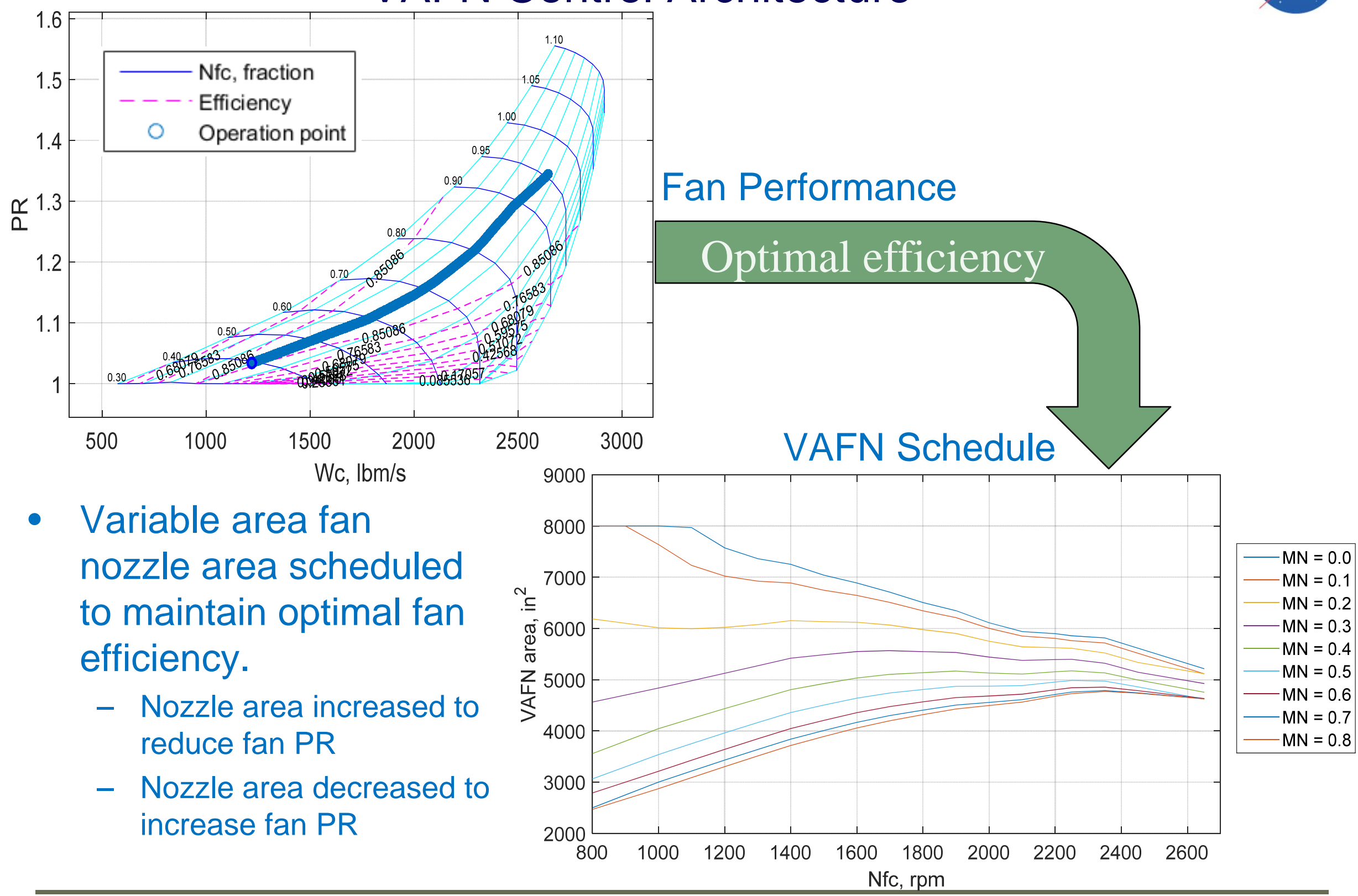




\section{Actuator Modeling}

- Fuel metering valve (FMV)

- First order actuator with a dynamic response much faster than rotor dynamics

- Variable bleed valve (VBV)

- First order actuator with a dynamic response much faster than rotor dynamics

- Variable area fan nozzle (VAFN)

- Research into VAFN actuation is ongoing

- Thermally activated shape memory alloy is being considered as a solution

- Advantages

- High power-to-weight ratio

- Challenges

- Maximum area reduction may not meet ideal nozzle requirements

- Slew rate may not meet engine transient requirements.

- Low technology readiness level (TRL)

- Due to uncertainty in actuator characteristics the AGTF30 utilizes an idealized actuation system as default, settling time equivalent to $0.8 \mathrm{~s}$. This value will be updated as more research becomes available. 


\section{VAFN response study}

- The AGTF30 was used for a simple study to find the minimum settling time requirement for a hypothetical shape memory alloy actuator.

- Traces show acceleration from Idle to Full power then a deceleration back to idle

- Plots b and c show divergence from ideal actuation (tracks control request perfectly)

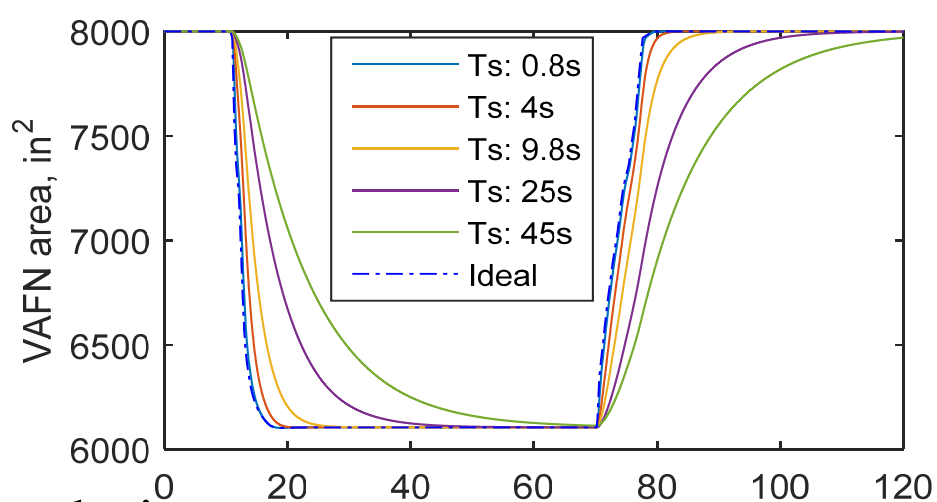

(a) Time, $\mathrm{s}$

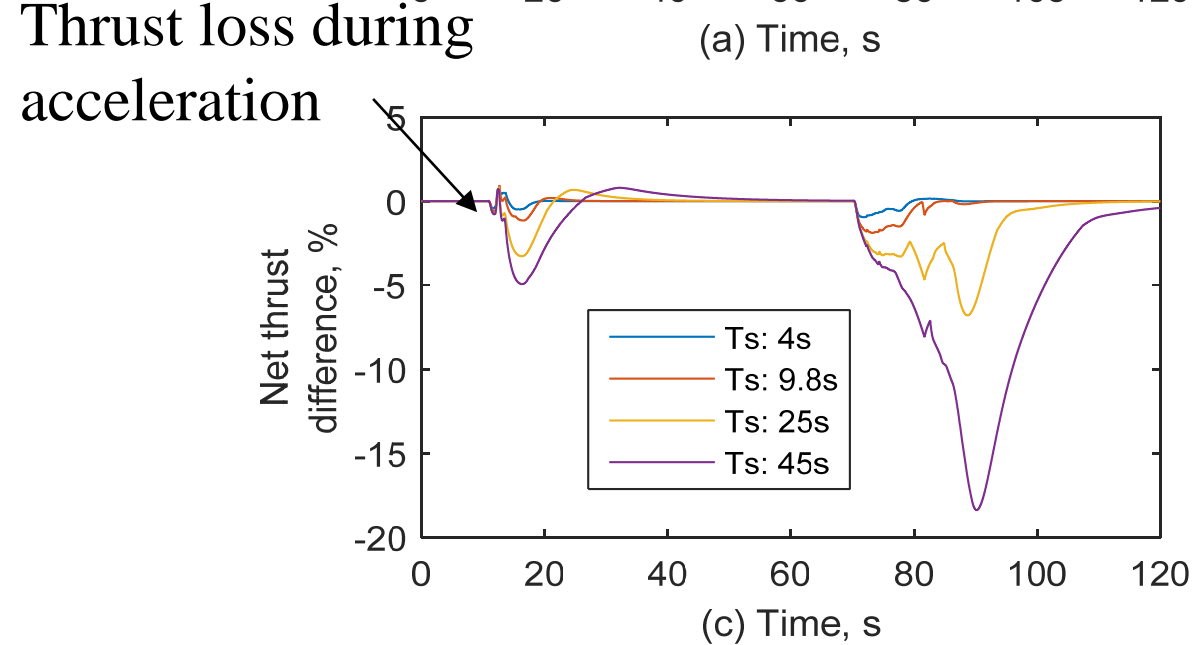

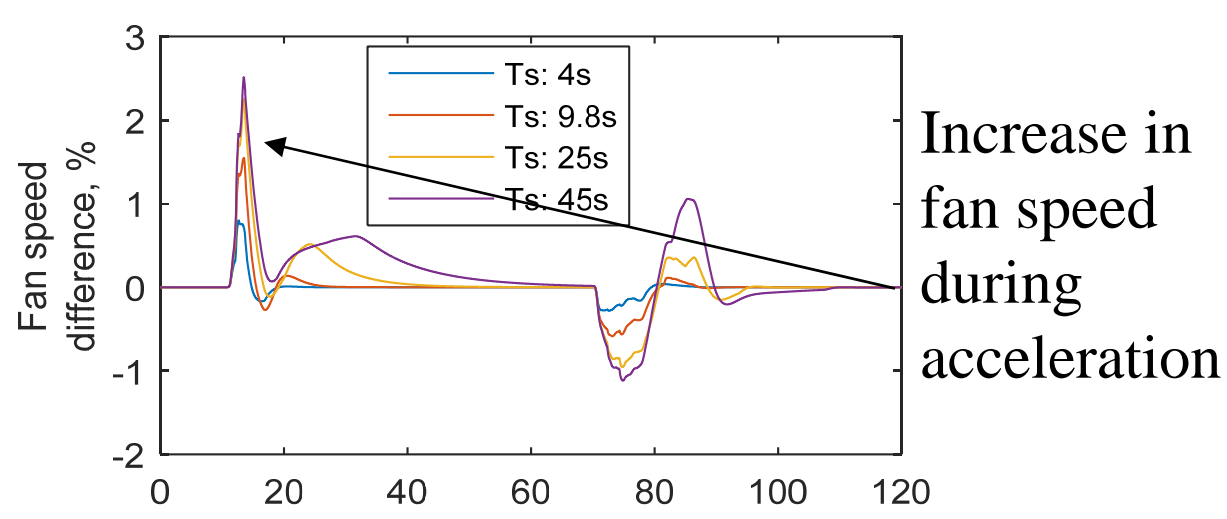

(b) Time, $\mathrm{s}$

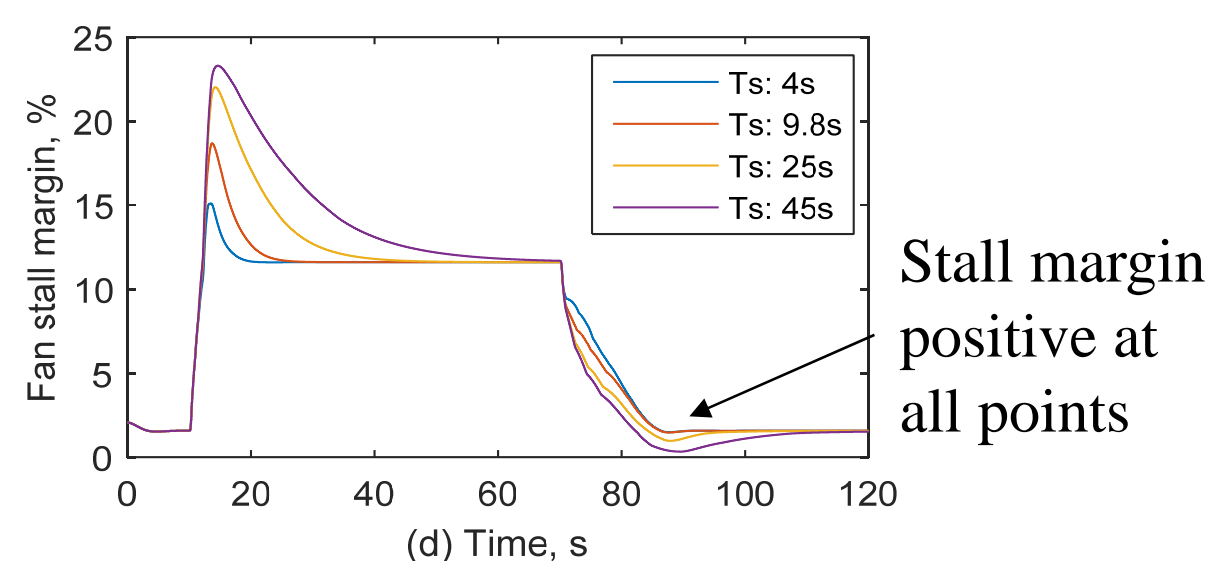

Settling times greater than 9.8s, generate large losses of thrust 


\section{Model Validation}

- Engine Model validation

- Simulation of an abbreviated mission profile

- Engine idling

- Acceleration from idle to full power followed by a take off at sea level static conditions

- Engine climbs to cruise $\frac{z}{\Sigma} 0.5$ at $35,000 \mathrm{ft}$

- Deceleration and descent

- Aircraft lands then returns to idle
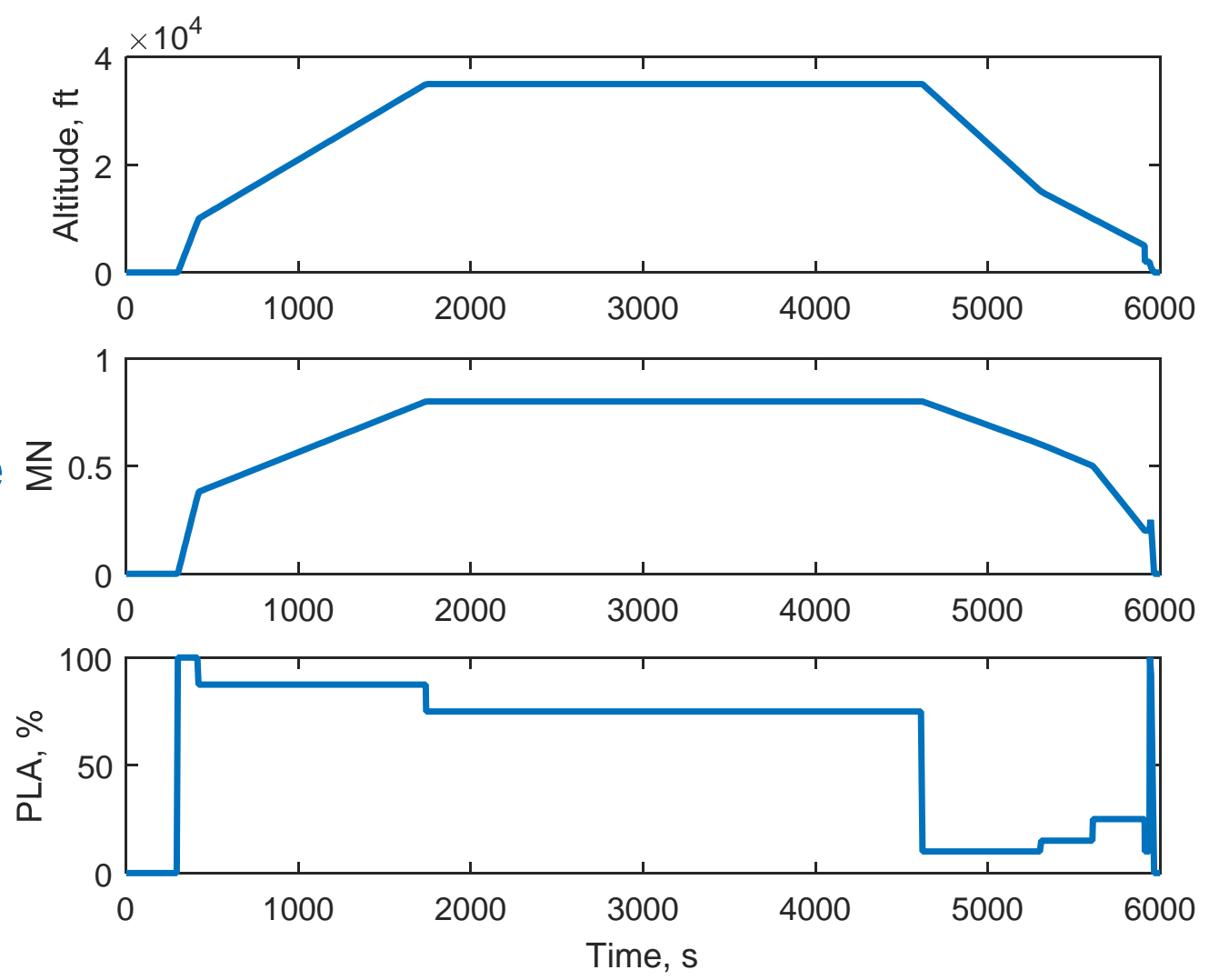
Model Validation, full profile
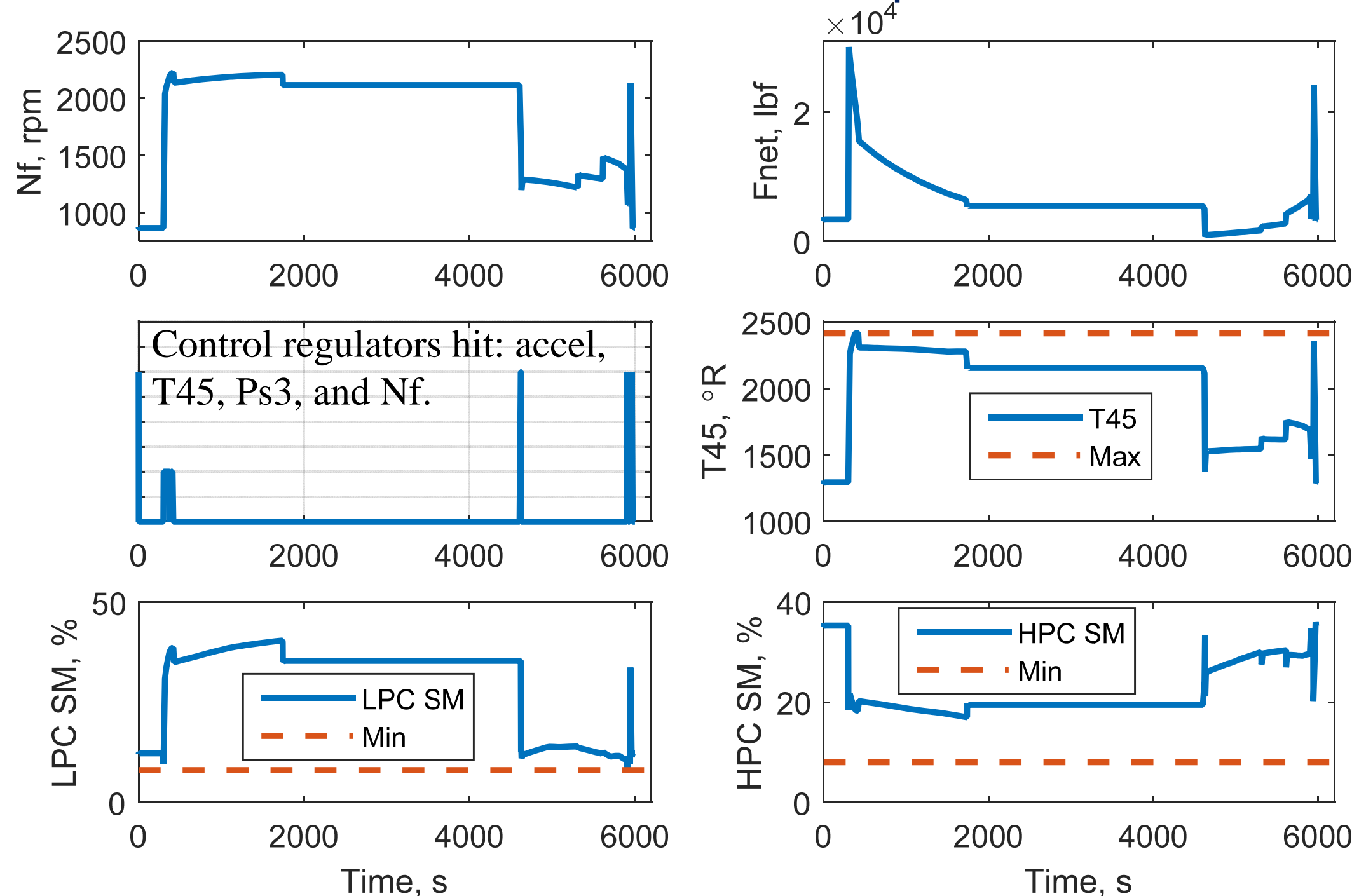

For the validation profile, all parameters remain within acceptable parameters and the engine performs as expected 
Model Validation, takeoff and climb
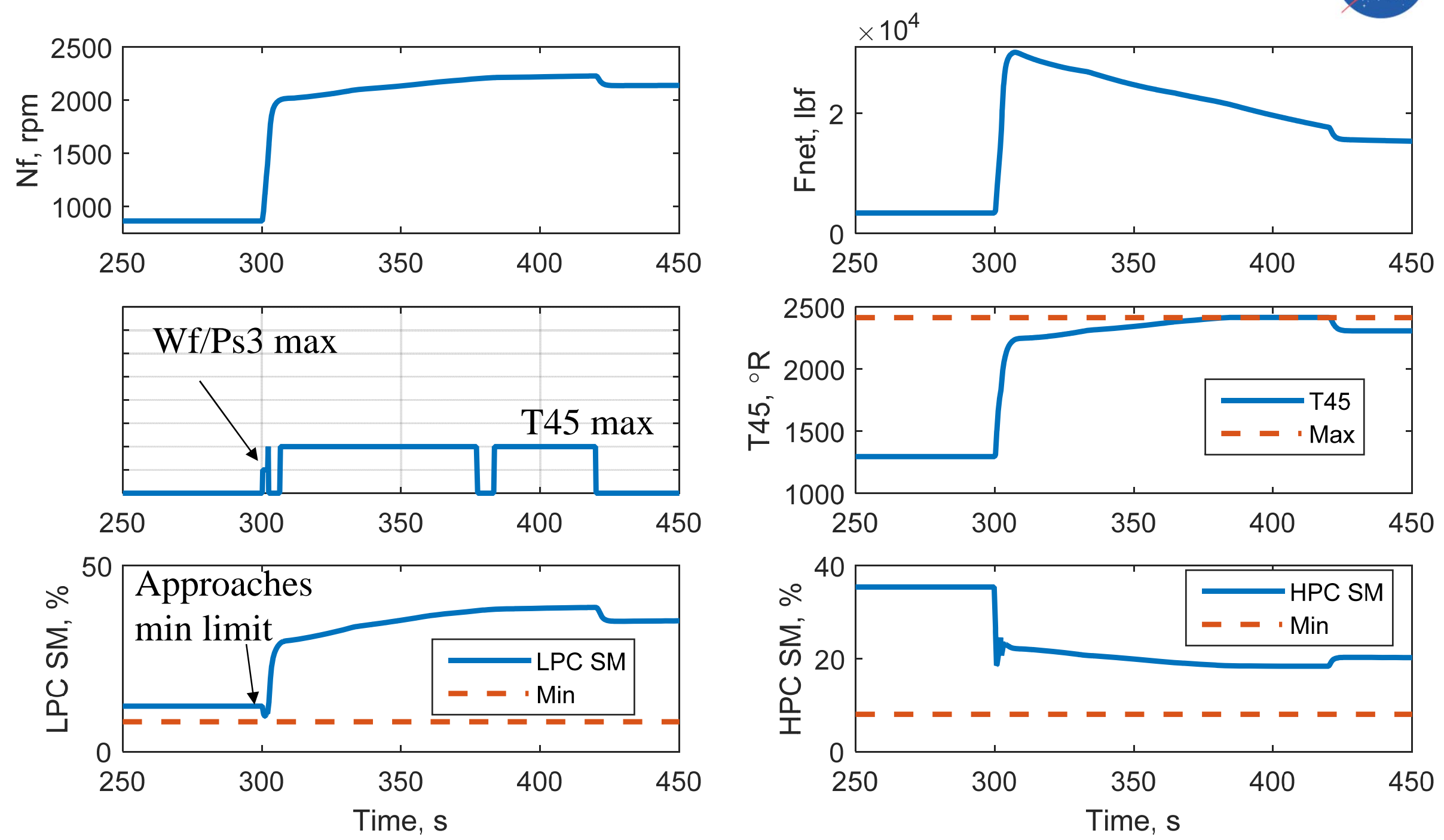

During acceleration and climb to altitude the control regulators act to maintain stall margin and maximum T45 limit 
Model Validation, approach and landing
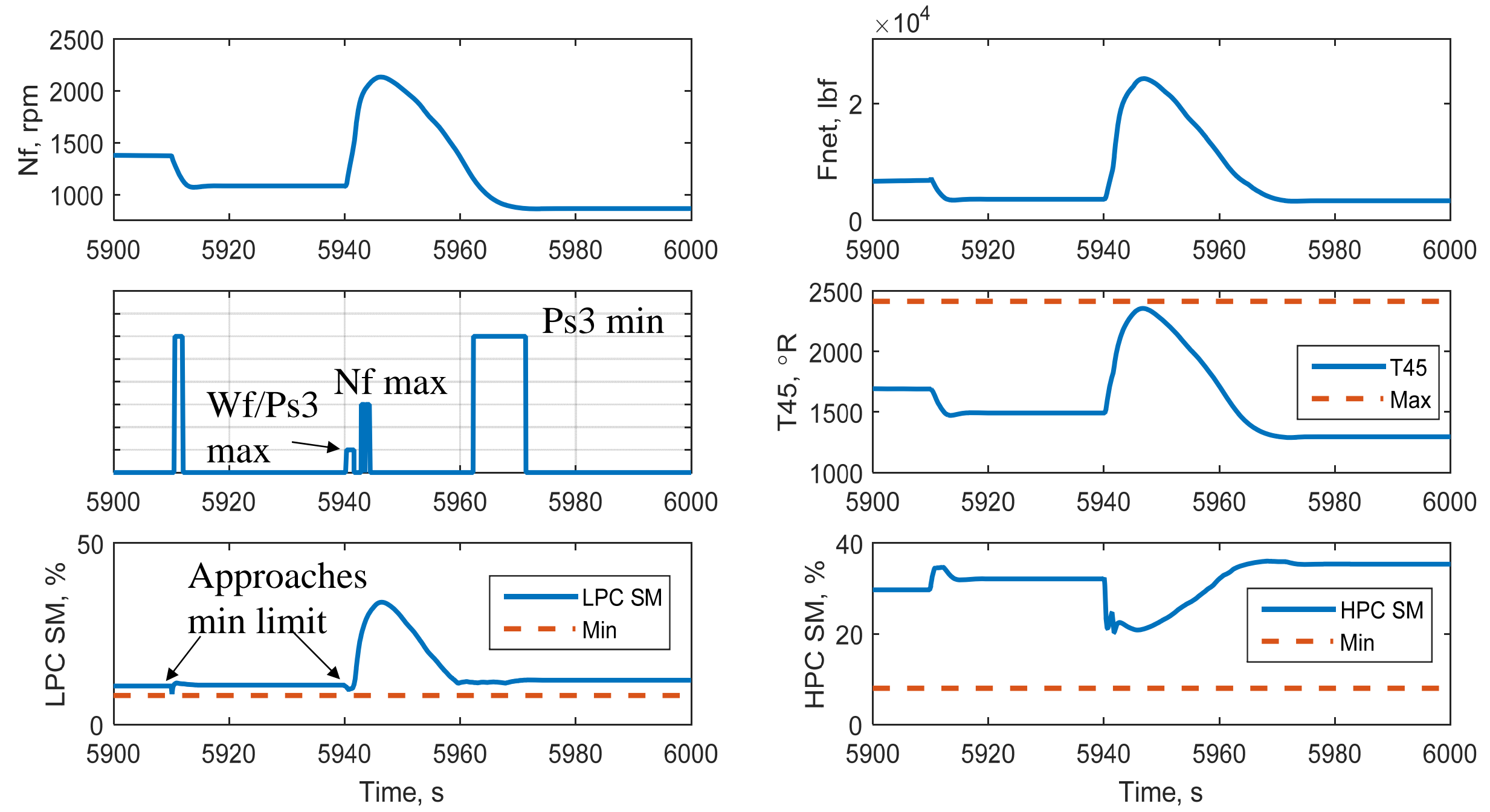

During approach and landing the control regulators act to maintain stall margin, maximum Nf limit and minimum Ps3 limit 
Simulation Operation

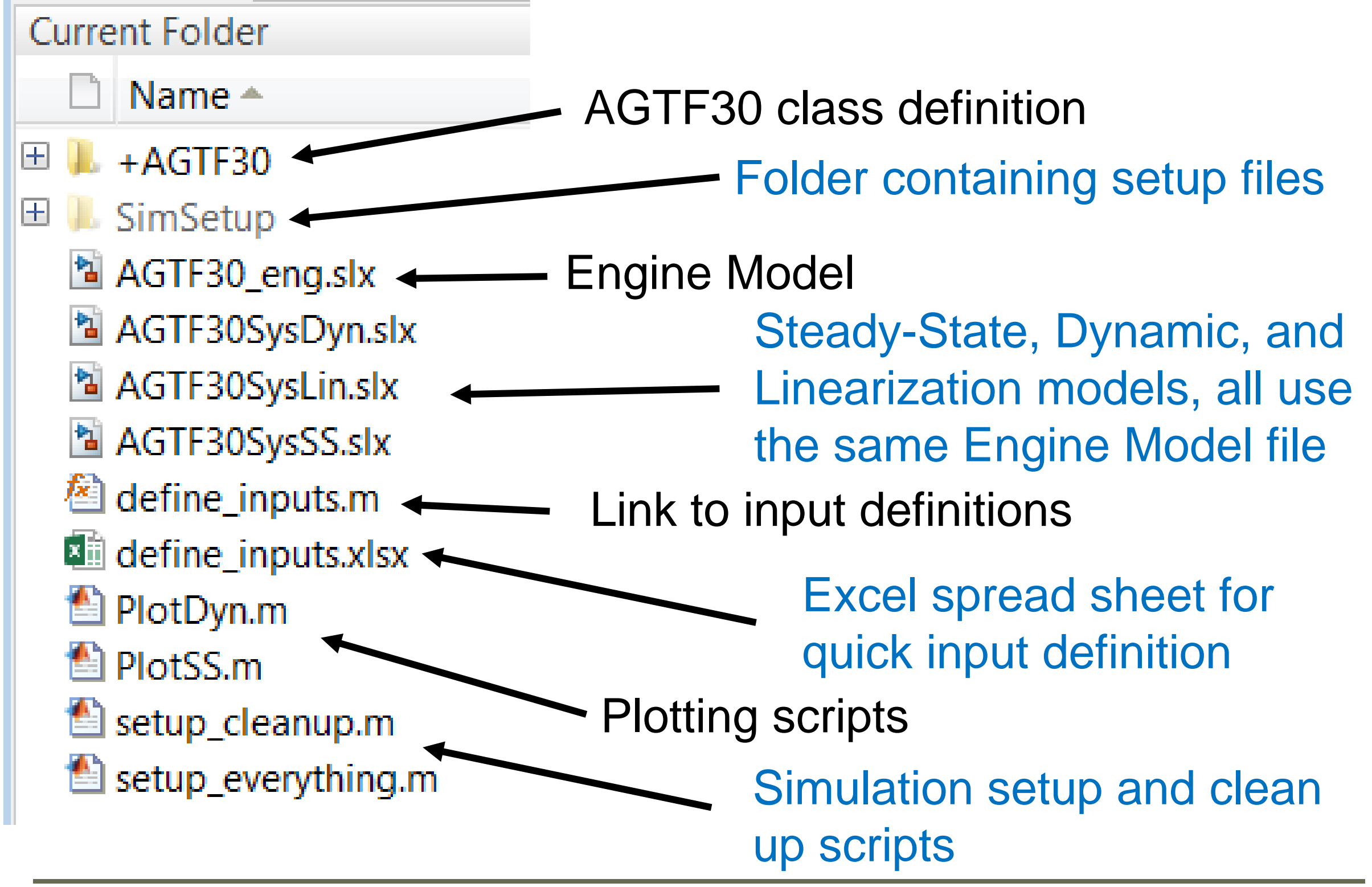


Setup Everything

MWS $=$

engName: 'AGTF30'

top_level: 'C: $\backslash$ AGTF30'

POp: '\'

Cntrl: [1x1 struct]

iDesign: 2

Inlet: [1x1 struct]

FAN: [1x1 struct]

LPC: [1x1 struct]

HPC: [1x1 struct]

HPT: [1x1 struct]

LPT: [1x1 struct]

VBV: [1x1 struct]

Burn: [1x1 struct]

NozByp: [1x1 struct]

NozCor: [1x1 struct]

Duct: [1x1 struct]

GearBox: [1x1 struct]

Sensor: [1x1 struct]

Act: [1x1 struct]

Shaft: [1x1 struct]

In: [1x1 struct]

Setup_everything.m - Loads bus objects and MATLAB Workspace (MWS) structure containing all simulation inputs

\begin{tabular}{|ll|}
\hline Amb & $1 \times 1$ Bus \\
\hline BackEng & $1 \times 1$ Bus \\
\hline BypassEng & $1 \times 1$ Bus \\
\hline CoreEng & $1 \times 1$ Bus \\
\hline FAN_Data & $1 \times 1$ Bus \\
\hline FrontEng & $1 \times 1$ Bus \\
\hline HPC_Data & $1 \times 1$ Bus \\
\hline HPT_Data & $1 \times 1$ Bus \\
\hline LPC_Data & $1 \times 1$ Bus \\
\hline LPT_Data & $1 \times 1$ Bus \\
\hline
\end{tabular}




\section{Input File}

- Enter inputs manually

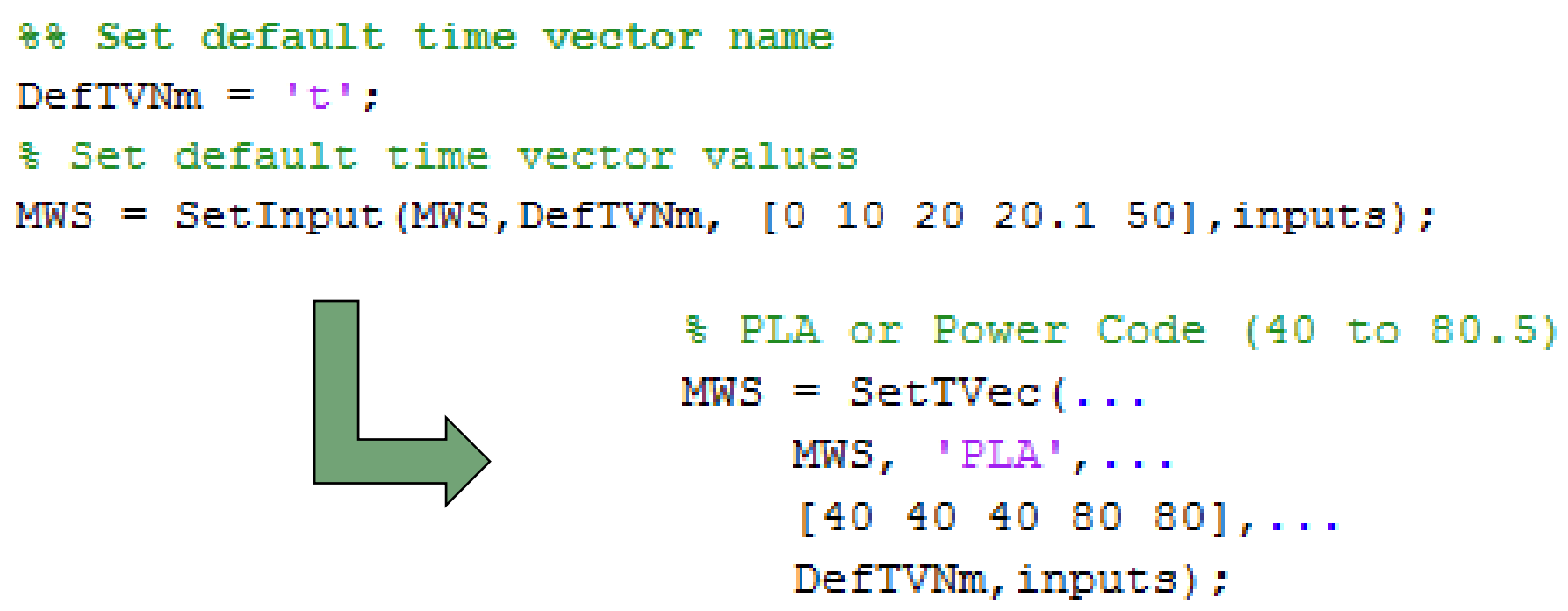

- Or use an excel spread sheet

\begin{tabular}{|c|c|c|c|c|c|c|c|c|}
\hline 4 & A & B & C & D & $E$ & $\mathbf{F}$ & G & $\mathrm{H}$ \\
\hline 1 & Description & Input Variable & $\begin{array}{l}\text { Associated } \\
\text { Time Vector }\end{array}$ & Data: & & & & \\
\hline 2 & time (s) & $t$ & NA & 0 & 10 & 20 & 20.1 & 50 \\
\hline 3 & Altitude $(\mathrm{ft})$ & Alt & $t$ & 0 & & & & \\
\hline 4 & Mach Number & $\mathrm{MN}$ & $t$ & 0 & & & & \\
\hline 5 & Delta Temperature (degF) & dT & $\mathrm{t}$ & 0 & & & & \\
\hline 6 & PLA (deg) & PLA & $\mathrm{t}$ & 40 & 40 & 40 & 80 & 80 \\
\hline
\end{tabular}




\section{Running the Model}

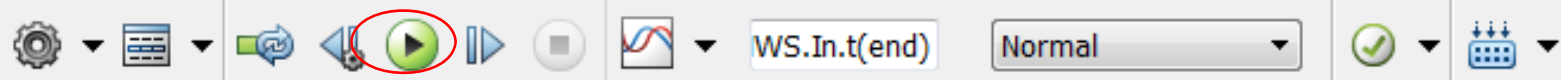

\section{Dynamic AGTF30 Advanced Geared Turbofan Engine System}

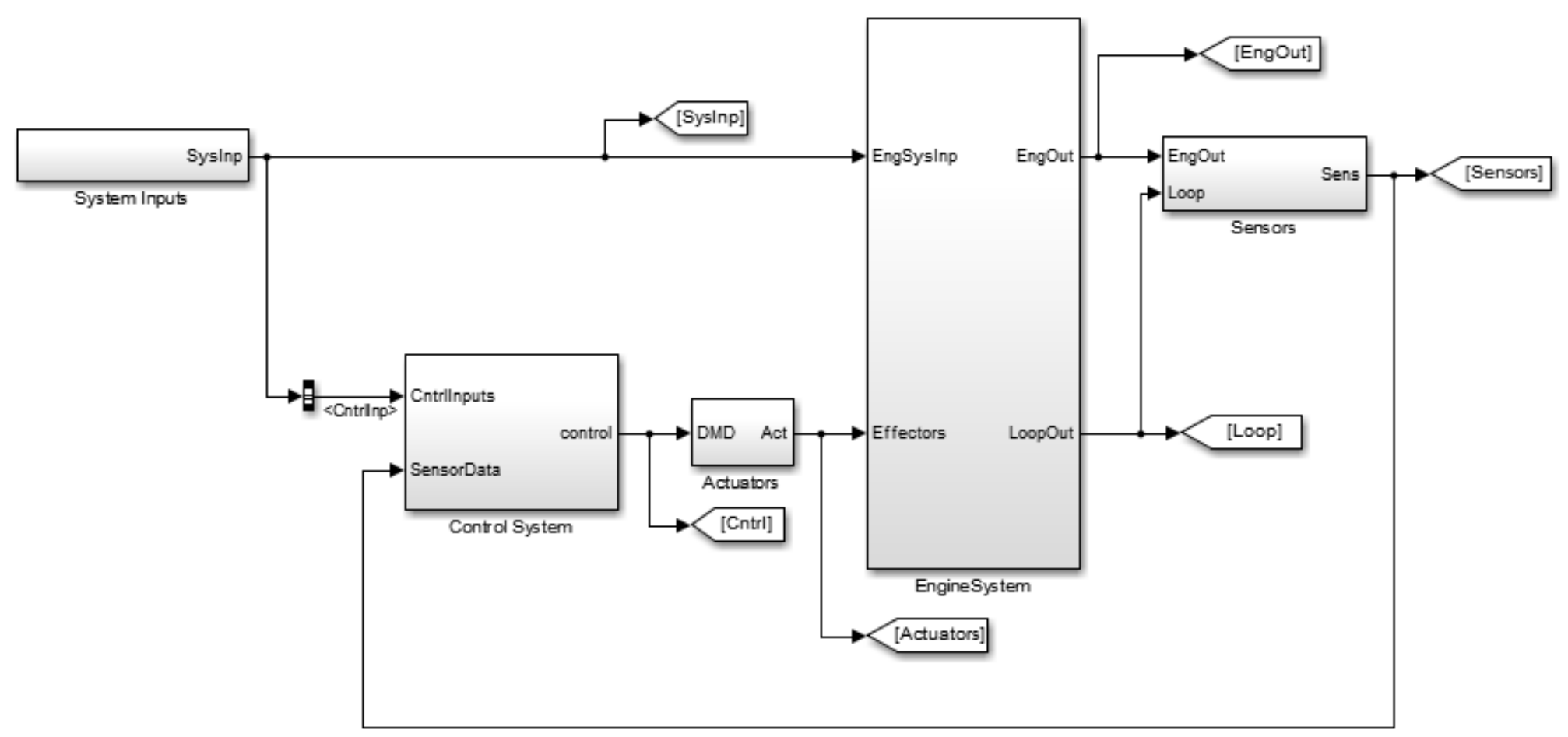




\section{Data Presentation}

$>$ out_Dyn

Data gathered in an

out_Dyn $=$ output structure.

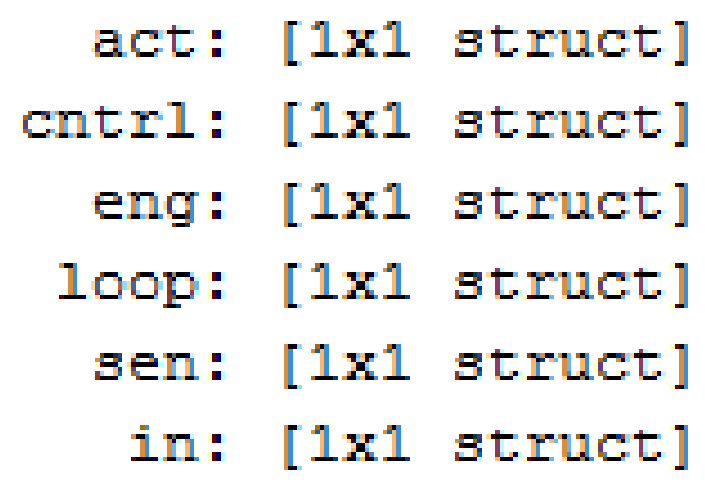

act: [1x1 struct]

cntr1: [1x1 struct]

eng: [1x1 struct]

loop: [1x1 struct]

sen: [1x1 struct]

in: [1x1 struct]

Formatted to make use of T-MATS auto plotting tools

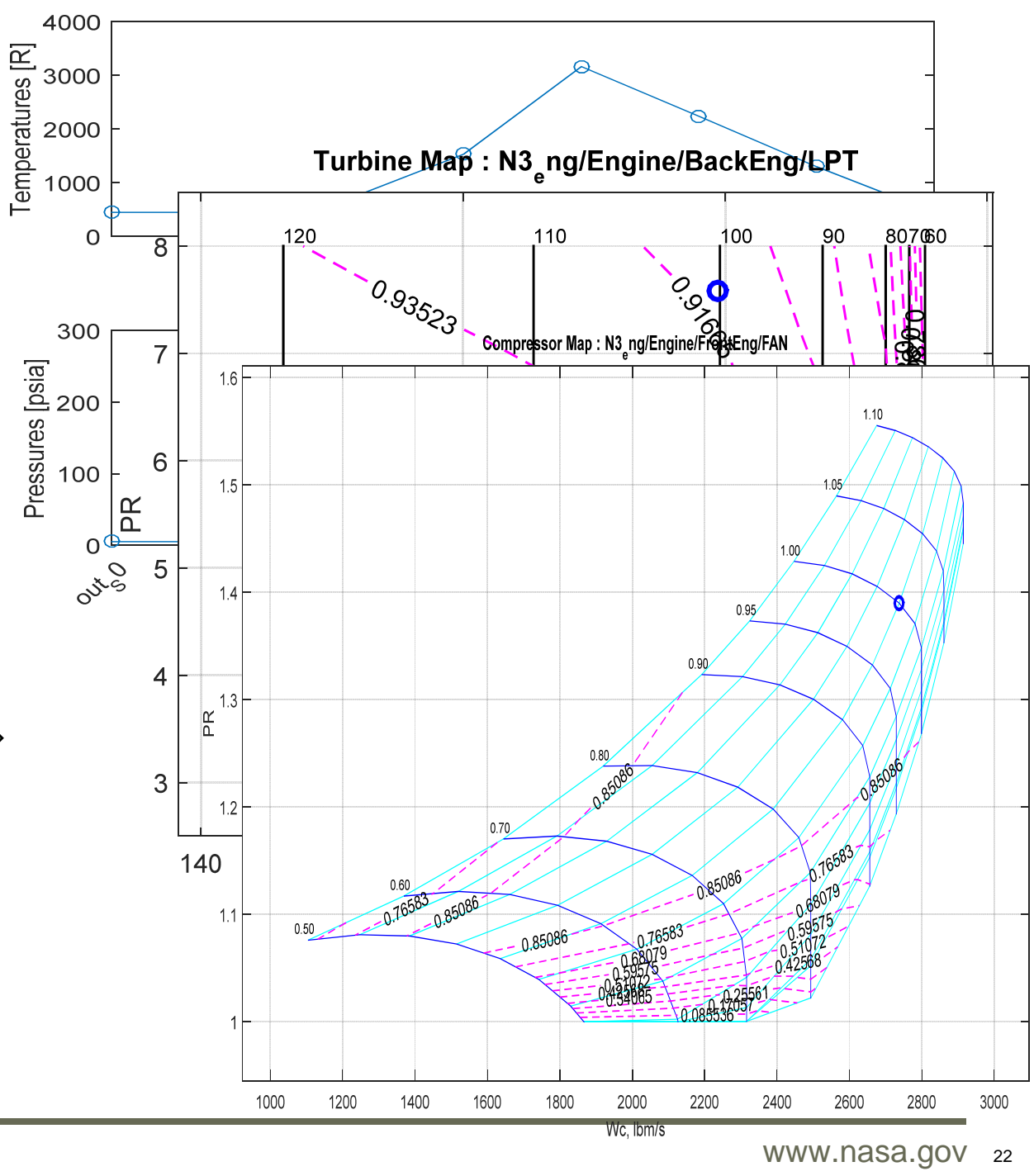




\section{Summary}

- A simulation of a next generation engine has been presented

- Advanced Geared Turbofan 30,000lbf (AGTF30)

- Ultrahigh bypass, small engine core, VAFN design

- Full envelope dynamic control system

- Built with the Toolbox for the Modeling and Analysis of Thermodynamic systems (T-MATS), https://github.com/nasa/T-MATS/releases

- Simulation awaiting approval to be made publically available

- Control system design described

- Fuel control based on classical architecture

- Variable geometries scheduled

- Sensitivity study on VAFN slew rate

- Shape memory alloy is currently being considered for use as the VAFN actuator, and actuator slew rate has been shown to be a limiting factor.

- Analysis of ideal and potential slew rates show significant performance degradation at actuator settling times greater than $9.8 \mathrm{~s}$

- AGTF30 simulation meets all requirements

- Simulation provides a realistic and dynamic platform for research into advanced geared turbofan technologies. 


\section{Acknowledgments}

Funding for this work was provided by NASA

Transformational Tools and Technology (TTT) project. 